\title{
O MEIO AMBIENTE ECOLOGICAMENTE EQUILIBRADO COMO DIREITO E DEVER FUNDAMENTAL NA CONSTITUIÇÃO FEDERAL DO BRASIL DE 1988
}

\author{
Lorena Silva Vasconcelos \\ Concludente do curso de Especialização em Direito Constitucional, \\ orientada pelo Prof. Ms. João Alfredo Mello (FA7) \\ lorenasv@netbandalarga.com.br \\ Sumário: Introdução. 1. Histórico da proteção jurídica ambiental no \\ Brasil e no mundo. 2. A teoria dos direitos fundamentais e o direito ao \\ meio ambiente ecologicamente equilibrado como direito fundamental. \\ 3. Direito fundamental ao meio ambiente equilibrado na $\mathrm{CF} / 88$. \\ 4. O dever constitucional de defesa e preservação do meio ambiente. \\ Conclusão. Referências.
}

Resumo: Este trabalho tem como objetivo principal a análise, através de pesquisa bibliográfica, do reconhecimento pela Constituição Federal do Brasil de 1988 do status de direito fundamental do direito ao meio ambiente ecologicamente equilibrado, assim como a apreciação da imposição ao Poder Público e a toda a sociedade do dever, também fundamental, de proteção do meio ambiente. Para tanto, constatou-se a existência de direitos fundamentais não inseridos no rol constante do artigo $5^{\circ}$, da atual Constituição Federal Brasileira, dentre os quais o direito ao meio ambiente ecologicamente equilibrado, previsto no artigo 225 da Carta Magna. Após, foi feita a análise do desenvolvimento constitucional e legislativo no que se refere à garantia do meio ambiente ecologicamente equilibrado no Brasil, que teve que ocorrer de forma que não fosse impedido o desenvolvimento econômico do país, oportunidade em que se inseriu na Constituição Federal o conceito de desenvolvimento sustentável. Buscou-se, ainda, demonstrar que o mesmo artigo 225 da Constituição Federal impôs não só aos poderes estatais, mas também à coletividade como um todo, o dever de defesa e preservação ambiental.

Palavras-chave: Meio ambiente ecologicamente equilibrado. Direito fundamental. Dever coletivo.

\section{INTRODUÇÃO}

O presente artigo tem por objetivo discorrer sobre uma problemática amplamente enquadrada nos dias atuais, qual seja, a atual crise ambiental por que passam as sociedades contemporâneas, consequência do desenvolvimento predatório, fator determinante para a inserção da preocupação com um meio ambiente equilibrado nas legislações mundiais.

Levantando-se a discussão acerca do status de direito fundamental que qualifica a garantia constitucional referente ao meio ambiente e também da imposição do dever de preservação, suscita-se a seguinte indagação: em que termos se pode afirmar ser a garantia de um meio ambiente ecologicamente equilibrado um direito fundamental, bem como um dever coletivo, de acordo com a Constituição Federal do Brasil de 1988, bem como de dever?

Com base nesse questionamento, o objetivo principal da pesquisa ora apresentada, é verificar se confere a Constituição Federal de 1988 ao meio ambiente ecologicamente equilibrado a 
qualificação de direito fundamental, e a forma como impõe a Carta Constitucional atualmente vigente o dever de preservação não só aos Poderes Públicos, mas também à coletividade como um todo.

\section{Como objetivos secundários apresentam-se:}

a) realizar pesquisa do histórico da proteção ambiental, dentro do conceito de desenvolvimento sustentável, nas constituições e na legislação brasileira;

b) identificar a existência de direitos fundamentais fora do rol trazido pelo art. $5^{\circ}$, da Constituição Federal de 1988, e se, dentre eles, insere-se o direito ao meio ambiente ecologicamente equilibrado;

c) identificar os destinatários do dever constitucional de defesa e preservação dos bens ambientais.

Inicia-se o estudo analisando-se, no caso específico do Brasil, como o meio ambiente ecologicamente equilibrado passou a ser objeto de proteção constitucional específica e integral, o que se deu com a Constituição Federal de 1988, apesar de já ter sido prevista a proteção ambiental em legislação infraconstitucional através da Lei ${ }^{\circ}$ 6.938/81, que trata da Política Nacional do Meio Ambiente.

$\mathrm{O}$ problema referente à tensão constante entre o direito ao meio ambiente e o direito ao desenvolvimento, assim como com o direito de propriedade, precisou ser solucionado, o que se fez através da criação do conceito de desenvolvimento sustentável, que representou a harmonização entre os interesses econômicos, individuais e ecológicos.

Estando diretamente relacionado com a preservação da vida humana e a dignidade do homem, o direito a um meio ambiente ecologicamente equilibrado passou a ser garantido como um direito fundamental de terceira dimensão, tanto no âmbito nacional quanto no internacional. Além disso, e visando uma proteção ambiental cada vez mais ampla e eficiente, impôs também à Constituição Brasileira, aos poderes estatais e a toda a coletividade, o dever, também fundamental, de defesa e preservação do meio ambiente.

Abordou-se, portanto, o desenvolvimento histórico da tutela ambiental no Brasil e no Mundo, seguida de intensa pesquisa bibliográfica nas obras dos autores mais renomados nas áreas do Direito Ambiental e do Direito Constitucional, tais como Paulo de Bessa Antunes, Celso Antonio Pacheco Fiorillo, Édis Milaré e José Joaquim Gomes Canotilho, bem como em artigos, legislação, jurisprudência e reportagens disponibilizadas nos diversos veículos de comunicação, visando verificar a forma como o direito ao meio ambiente ecologicamente equilibrado passou a ser enquadrado como um direito humano fundamental e, ainda, como a Constituição Federal de 1988 passou a impor, de forma subjetivamente ampla, o dever de proteção desse meio ambiente, tendo sido, desde então, reconhecida a importância da proteção ambiental para uma sadia qualidade de vida das atuais e futuras gerações.

\section{HistóRICO dA PROTEÇão JURídica AMBIENTAL No BRASIL E NO MUNDO}

Tratando-se de questão relativamente recente na história da humanidade, a preocupação com o meio ambiente passou a se mostrar presente somente nos textos constitucionais elaborados a partir da década de 1970. Essa mudança ocorreu devido, principalmente, à realização da Conferência das Nações Unidas sobre Meio Ambiente de Estocolmo (Suécia) em 1972, primeiro evento de amplitude mundial a tratar da importância de se buscar um meio ambiente saudável. A Declaração de Estocolmo, que consagrou o princípio de que o ser humano tem direito à liberdade, à igualdade e a uma vida com condições adequadas de sobrevivência, num meio ambiente que lhe permita usufruir de uma vida digna, consagrou-se como um marco no que se refere à regulação jurídico-internacional de proteção ambiental. 
Logo após a Conferência de Estocolmo, vários tratados internacionais, bilaterais e multilaterais sobre meio ambiente foram firmados. Além disso, diversos países modificaram seus instrumentos jurídicos, passando a reconhecer com maior responsabilidade e comprometimento a importância do meio ambiente equilibrado. As Constituições de Portugal (1976, no art. 66) e da Espanha (1978, no art. 45) foram as primeiras a relacionarem o direito ao meio ambiente sadio com o direito à vida.

Em seguida, em 1992, realizou-se o encontro denominado Conferência das Nações Unidas sobre o Meio Ambiente e Desenvolvimento, realizado no Rio de Janeiro, no período de 3 a 14 de junho de 1992, que ficou conhecido como Cúpula da Terra ou RIO 92 e tinha como principal objeto de discussão os interesses ambientais globais.

O direito humano ao meio ambiente sadio foi reafirmado pela Declaração do Rio de Janeiro sobre o Meio Ambiente (1992) que, reforçando os princípios da Declaração de Estocolmo, objetivou estabelecer uma nova ordem de cooperação entre a sociedade e o Poder Público na proteção do meio ambiente e introduziu novos princípios garantidores do desenvolvimento sustentável, tendo em vista os interesses gerais, bem como a integridade global do meio ambiente. Importante ressaltar que referido evento, ocorrido no Rio de Janeiro, deu origem a outros importantes instrumentos de proteção ambiental, dentre os quais destacam-se a Agenda 21 e a Convenção sobre a Diversidade Biológica.

Cabe, ainda, destacar no âmbito internacional, o importante Protocolo de Quioto, estabelecido em 11 de dezembro de 1997, que, entretanto, somente entrou em vigor em 16 de fevereiro de 2005. Trata-se de um Protocolo, constituído por vinte e oito artigos no qual as partes qualificadas como países desenvolvidos assumem o compromisso de reduzirem suas emissões de gases causadores do efeito estufa em patamares determinados, a fim de promoverem o desenvolvimento sustentável. Não foi estabelecida, no Protocolo de Quioto, meta para a redução das emissões de gases poluentes para os países em desenvolvimento, como o Brasil; porém, foi determinado que esses países também devem implementar sistemas de desenvolvimento sustentável para a melhoria do ambiente.

No Brasil, a preocupação com o meio ambiente equilibrado somente ganhou tratamento legislativo específico em 1981, com a instituição da Política Nacional do Meio Ambiente, através da Lei ${ }^{\circ}$ 6.938/81, primeiro instrumento jurídico nacional a conceituar o meio ambiente. Até então, não havia definição clara no ordenamento jurídico pátrio referente à políticas públicas ambientais.

No plano constitucional, verifica-se que as Constituições Brasileiras que precederam a Carta de 1988 não estabeleciam regras específicas sobre o meio ambiente. Apenas a Constituição de 1946 fez alguma menção sobre o Direito Ambiental, limitando-se a determinar a competência da União para legislar sobre a proteção da água, das florestas, entre outros. A atual Constituição Federal foi, portanto, a primeira a tutelar nacionalmente o meio ambiente de maneira específica, conforme as palavras de José Afonso da Silva (2002, p.46): “a Constituição de 1988 foi a primeira a tratar deliberadamente da questão ambiental".

Além disso, a Constituição de 1988, considerada uma das mais abrangentes e avançadas em matéria de tutela ambiental, foi a pioneira no emprego da expressão "meio ambiente", tendo dedicado todo um capítulo à disciplina da relação do Poder Público e do cidadão brasileiro com o meio ambiente.

\section{Como destaca Édis Milaré (1991), a atual Carta Constitucional é um}

[...] marco histórico de inegável valor, dado que as Constituições que precederam a de 1988, jamais se preocuparam com a proteção do meio ambiente de forma específica e global. 
Nelas, sequer uma vez, foi empregada a expressão 'meio ambiente', a revelar total despreocupação com o próprio espaço em que vivemos. (Milaré, 1991, p. 3)

No plano infraconstitucional, além da anteriormente citada Lei ${ }^{0}$ 6.938/81, instituidora da Política Nacional do Meio Ambiente, se deve destacar a Lei Ordinária n ${ }^{\circ}$ 7.347/85, que disciplina a Ação Civil Pública, cabível nos casos de danos causados ao meio ambiente e outros bens de valor artístico, paisagístico, estético e histórico.

Após a constitucionalização da questão ambiental e a assinatura de diversos tratados multilaterais sobre o meio ambiente, o Brasil tem cada vez mais buscado dar efetividade ao preceito fundamental de um meio ambiente equilibrado, figurando atualmente como parte nos principais documentos internacionais de proteção ao meio ambiente, tendo, inclusive, ratificado muitos deles.

\section{A TEORIA dOS DIREITOS FUNDAMENTAIS E O DIREITO AO MEIO AMBIENTE ECOLOGICAMENTE EQUILIBRADO COMO DIREITO FUNDAMENTAL}

Tradicionalmente, a doutrina jurídica apresenta uma classificação dos direitos humanos fundamentais tanto histórico-cronológica como material, subdividindo-os em Direitos Humanos de Primeira, Segunda e Terceira Geração/Dimensão. Importante ressaltar que há autores que consideram, ainda, a existência de direitos fundamentais de quarta e até de quinta dimensão, não sendo a existência dessas duas últimas categorias entendimento unânime na doutrina.

Os Direitos de Primeira Geração, tendo surgido com a Revolução Francesa, em 1789, preservam as garantias individuais do ser humano. São os direitos da liberdade, principalmente os direitos civis e políticos. Esses foram os primeiros direitos fundamentais a terem status constitucional no Brasil e, também, nos demais países.

A Segunda Geração dos Direitos Humanos surgiu no final do século XIX e início do século XX, com a Revolução Industrial e o advento do Estado Social. Esses direitos de segunda dimensão buscam, basicamente, a garantia dos chamados direitos sociais, fundados no princípio da igualdade. Não são direitos exercidos contra o Estado, já que exigem, para sua efetivação, uma ação estatal positiva, ou seja, uma prestação estatal. Se referem, mais especificamente, aos direitos dos trabalhadores e à implementação de políticas visando o desenvolvimento social.

Os Direitos Humanos de Terceira Geração, por sua vez, surgiram durante e após a Segunda Guerra Mundial e são representados pelos direitos difusos. São também chamados de direitos da fraternidade ou da solidariedade. Esses direitos tratam de temas destinados a toda a humanidade e se referem, principalmente, ao desenvolvimento, à paz, ao meio ambiente, à comunicação e ao patrimônio comum da humanidade, como, por exemplo, a proteção do patrimônio histórico, cultural e ambiental.

Na prática, porém, costuma-se, na maioria das vezes, associar os direitos humanos a liberdades meramente individuais. Devido a essa associação equivocada, a atuação direcionada à proteção no âmbito do direito internacional, e também no do direito ambiental, dos direitos humanos de terceira dimensão representa grande desafio jurídico.

Tratando-se de um direito difuso e enquadrando-se na categoria de Direito Humano de Terceira Geração, o direito de viver em um ambiente ecologicamente equilibrado, extensão do direito à vida, conforme entendimento doutrinário majoritário, foi internacionalmente consagrado como direito fundamental do homem. Esse reconhecimento do direito ao meio ambiente sadio como direito fundamental representa importante marco na construção de uma sociedade democrática, 
participativa e socialmente solidária. Nas palavras de Paulo de Bessa Antunes (2005, p. 25): "o primeiro e mais importante princípio do Direito Ambiental é: o direito ao ambiente é um direito humano fundamental".

Como consequência da classificação desse direito fundamental ambiental como direito difuso, surge a característica da indisponibilidade do bem ambiental, decorrência do interesse público pela preservação do meio ambiente e da atribuição da qualidade pública a esse bem de uso comum do povo. Além disso, essa indisponibilidade visa também à preservação do meio ambiente em atenção às gerações futuras.

Entretanto, dentre os direitos fundamentais, é perfeitamente possível que, diante de uma situação concreta, dois ou mais deles entrem em conflito. E, no que se refere ao direito ao meio ambiente ecologicamente equilibrado, pode-se facilmente visualizar possíveis conflitos tanto com o direito de propriedade como com o direito ao desenvolvimento econômico.

Quanto ao confronto do direito ao meio ambiente ecologicamente equilibrado com o direito de propriedade, deve-se ressaltar que a constitucionalização daquele direito fundamental tem servido também para contrabalançar as prerrogativas tradicionais do direito de propriedade, dando ensejo a novas e fortalecendo antigas limitações a esse direito. Em determinadas circunstâncias, o não uso é a conduta mais apropriada à proteção ambiental, o que representa uma enorme limitação ao direito de propriedade. Porém, a propriedade privada não obrigatoriamente exclui a preservação ambiental, como afirma o autor europeu François Ost (1995, p. 74): “O proprietário exclusivo pode, também ele, desempenhar o papel de guardião da natureza, se a sua preocupação não se reduzir a extrair-lhe de imediato o maior lucro possível.". Portanto, se a função social da propriedade for devidamente cumprida, conforme os fins sociais, e se for observado o conceito do desenvolvimento sustentável, a seguir explicitado, vislumbrar-se-á a adequada aplicação do instrumento da ponderação entre esses direitos fundamentais aparentemente em conflito.

O outro conflito citado se refere ao direito ao desenvolvimento econômico de um lado e o meio ambiente de outro. Para muitos, esses direitos são completamente opostos e, portanto, inconciliáveis. Porém, José Afonso da Silva não corrobora esse entendimento, afirmando que "o conforto que o dinheiro compra não constitui todo o conteúdo de uma boa qualidade de vida” (Silva, 2002, p. 25).

Também classificado como direito fundamental de terceira geração, o direito ao desenvolvimento pode e deve ser harmonizado com o direito ao meio ambiente ecologicamente equilibrado, chegando-se ao conceito conhecido como "desenvolvimento sustentável", expressão empregada pela primeira vez no chamado Relatório Brundtland ${ }^{1}$, de 1987, que o definiu como o desenvolvimento que atende às necessidades das gerações atuais sem comprometer o atendimento das necessidades das futuras gerações.

Portanto, a solução para o impasse entre economia e meio ambiente é a concretização do princípio do desenvolvimento sustentável, que determina a inclusão nos modelos de desenvolvimento da variante do meio ambiente, buscando a concordância prática entre os direitos em conflito a fim de não esvaziar o conteúdo de nenhum deles.

Importante destacar, porém, uma particularidade do direito fundamental ao meio ambiente ecologicamente equilibrado, no que se refere aos demais direitos fundamentais: a obrigação a que este direito está sujeito não é unicamente do Estado, mas também da sociedade. Ou seja, a efetiva garantia desse direito fundamental depende tanto das políticas implementadas

1 O Relatório Brundtland foi elaborado e apresentado às Nações Unidas em 1987 pela Comissão Mundial do Meio Ambiente e Desenvolvimento, constuída num encontro em Nairóbi, em 1982, para avaliar as medidas adotadas pelos Estados nos dez anos que sucederam à Declaração de Estocolmo de 1972. 
pelo Poder Público como da participação ativa da coletividade como um todo, numa espécie de responsabilidade compartilhada.

De acordo com Édis Milaré (2007), a participação popular na formulação e execução de políticas públicas de preservação do meio ambiente também é um direito fundamental, podendo-se afirmar que a preservação do equilíbrio ecológico é condição indispensável para a proteção da qualidade de vida e sua efetivação é dever de todos, cabendo ao Estado regular as políticas adequadas ao caso.

Afirma o renomado jurista Alexandre de Moraes, que deve-se buscar, para a proteção do meio ambiente, a conciliação entre o Direito Constitucional e o Direito Internacional, "permitindo uma evolução nas tradicionais noções de soberania, direito de propriedade, interesse público e privado" (Moraes, 2006, p. 775) Essa necessária conciliação se justifica no fato de o meio ambiente não obedecer às fronteiras geograficamente estabelecidas pelo homem, devendo sua proteção ter âmbito global, razão pela qual deve ele ser considerado patrimônio comum de toda a humanidade, evitando-se, dessa forma, a afetação de um bem natural a uma finalidade exclusivamente individual. Somente dessa forma, esse direito humano fundamental de terceira geração será devidamente protegido e garantido para as atuais e futuras gerações.

Nesse contexto, face à tendência contemporânea de preocupação com os interesses difusos, e particularmente com o meio ambiente, a Declaração sobre o Ambiente Humano, elaborada na Conferência das Nações Unidas em Estocolmo, Suécia, em junho de 1972, consagrou internacionalmente o direito ao meio ambiente sadio como um direito humano fundamental:

O homem tem o direito fundamental à liberdade, à igualdade e ao desfrute de condições
de vida adequadas, em um meio ambiente de qualidade tal que lhe permita levar uma vida
digna, gozar de bem-estar e ser portador solene de obrigação de proteger e melhorar o
meio ambiente, para as gerações presentes e futuras. [...] Os recursos naturais da Terra,
incluídos o ar, a água, o solo, a flora e a fauna e, especialmente, parcelas representativas dos
ecossistemas naturais, devem ser preservados em benefício das gerações atuais e futuras,
mediante um cuidadoso planejamento ou administração adequados. Deve ser mantida e,
sempre que possível, restaurada ou melhorada a capacidade da Terra de produzir recursos
renováveis vitais. O homem tem a responsabilidade especial de preservar e administrar
judiciosamente o patrimônio representado pela flora e fauna silvestres, bem assim o
seu'habitat', que se encontram atualmente em grave perigo, por uma combinação de
fatores adversos. Em consequência, ao planificar o desenvolvimento econômico, deve
ser atribuída importância à conservação da natureza, incluídas a flora e a fauna silvestres.

Através da Declaração de Estocolmo, foi aberto o caminho para que as Constituições supervenientes reconhecessem o direito ao meio ambiente ecologicamente equilibrado como um direito fundamental, sendo o princípio acima transcrito a mais antiga declaração que vincula direitos humanos e proteção ambiental. Esse direito ambiental foi, conforme descrito no tópico anterior, reafirmado como direito fundamental por consequentes instrumentos internacionais e pelas Constituições de diversos países, momento a partir do qual se começou a dar a devida importância a esse direito humano incontestavelmente fundamental.

\section{Direito FUndamental AO MEIO AMBIENTE EQUILIBRAdo NA Constituição Federal de 1988}

Apresentando capítulo específico dedicado à proteção ambiental, a Constituição de 1988 representa considerável avanço na tutela ambiental, tendo em vista reconhecer como direito fundamental o direito ao meio ambiente equilibrado, conforme palavras de Alexandre de Moraes (2006): 
A Constituição Federal de 1988 consagrou como obrigação do Poder Público a defesa, preservação e garantia de efetividade do direito fundamental ao meio ambiente ecologicamente equilibrado, bem de uso comum do povo e essencial à sadia qualidade de vida. (MORAES, 2006, p. 774)

O caput e $\S 1^{\circ}$ do art. 225 da $\mathrm{CF} / 88$ prevêem:

Art. 225. Todos têm direito ao meio ambiente ecologicamente equilibrado, bem de uso comum do povo e essencial à sadia qualidade de vida, impondo-se ao Poder Público e à coletividade o dever de defendê-lo e preservá-lo para as presentes e futuras gerações.

$\S 1^{\circ}$ - Para assegurar a efetividade desse direito, incumbe ao Poder Público:

I - preservar e restaurar os processos ecológicos essenciais e prover o manejo ecológico das espécies e ecossistemas;

II - preservar a diversidade e a integridade do patrimônio genético do País e fiscalizar as entidades dedicadas à pesquisa e manipulação de material genético;

III - definir, em todas as unidades da Federação, espaços territoriais e seus componentes a serem especialmente protegidos, sendo a alteração e a supressão permitidas somente através de lei, vedada qualquer utilização que comprometa a integridade dos atributos que justifiquem sua proteção;

IV - exigir, na forma da lei, para instalação de obra ou atividade potencialmente causadora de significativa degradação do meio ambiente, estudo prévio de impacto ambiental, a que se dará publicidade;

V - controlar a produção, a comercialização e o emprego de técnicas, métodos e substâncias que comportem risco para a vida, a qualidade de vida e o meio ambiente;

VI - promover a educação ambiental em todos os níveis de ensino e a conscientização pública para a preservação do meio ambiente;

VII - proteger a fauna e a flora, vedadas, na forma da lei, as práticas que coloquem em risco sua função ecológica, provoquem a extinção de espécies ou submetam os animais à crueldade.

Verifica-se, com a leitura do caput do dispositivo transcrito, ter sido classificado o meio ambiente como bem de uso comum do povo, bem indisponível que, nos termos constitucionais, deve ser protegido com a utilização de todos os meios legislativos, administrativos e judiciais disponíveis.

Já o $\S 1^{\circ}$ de referido artigo estabelece obrigações ambientais a serem cumpridas pelo Poder Público. Porém, como se pode observar da leitura do art. 225 da CF/88 por inteiro, a Constituição Federal, além de garantir um amplo direito de informação em relação à proteção do meio ambiente, determina à sociedade responsabilidades conjuntas com o Poder Público. O Estado deve fornecer os meios instrumentais necessários à implementação do direito ao meio ambiente ecologicamente equilibrado e a coletividade, por sua vez, deve se abster das práticas nocivas ao meio ambiente e participar ativamente das atividades que visem à proteção ambiental. Portanto, clara é a necessidade da gestão integrada e participativa entre a sociedade e o Estado acerca da conservação ambiental (princípio da cooperação), requisito indispensável para a eficácia das políticas públicas a esse fim destinadas.

O princípio da cooperação, uma atuação conjunta do Estado e sociedade, ocorre na escolha de prioridades e nos processos decisórios. Ele está na base dos instrumentos normativos criados com o objetivo de aumentar a informação e a ampliação de participação nos processos da política ambiental, dotando-a de flexibilidade, legitimidade e eficácia. (Mukai, 2002, p. 32)

O que é realmente inovador no art. 225 é o reconhecimento da indissolubilidade do vínculo Estado-Sociedade civil. Esse vínculo, entre os interesses públicos e privados, redunda em verdadeira noção de solidariedade em torno de um bem comum. (Canotilho, 2007, p. 197) 
$\mathrm{O}$ art. 225 da CF/88 deve ser interpretado levando-se em consideração também os seguintes dispositivos constitucionais: art. $1^{\circ}$, III, que consagra o princípio da dignidade da pessoa humana como fundamento da República; art. $3^{\circ}$, II, que estabelece o desenvolvimento nacional como objetivo da República; e art. $4^{\circ}$, IX, que determina que o Brasil reja-se, em suas relações internacionais, pelo princípio da cooperação entre os povos para o progresso da humanidade. A interpretação conjunta desses dispositivos demonstra que a atual Carta Constitucional Brasileira permite uma proteção ambiental mais ampla e efetiva aliada a um desenvolvimento sustentável.

Há algum tempo é unânime na doutrina e jurisprudência o entendimento de que os direitos fundamentais previstos na Constituição Federal de 1988 não se restringem àqueles previstos no Título II, ou, mais especificamente, no art. $5^{\circ}$ da $\mathrm{CF} / 88$, que apresenta rol meramente exemplificativo. O próprio $\S 2^{\circ}$ do mesmo art. $5^{\circ}$ da $\mathrm{CF} / 88$ determina que "os direitos e garantias expressos nesta Constituição não excluem outros decorrentes do regime e dos princípios por ela adotados, ou dos tratados internacionais em que a República Federativa do Brasil seja parte.” Daí se conclui que a atual Constituição Brasileira adota uma compreensão material - e não formal do direito fundamental.

Considera-se, inclusive, que a atual Constituição evoluiu ideologicamente em relação às Constituições anteriores, tendo ampliado bastante as garantias constitucionais e avançado consideravelmente na abordagem dos direitos fundamentais. Dentre essas evoluções ocorridas, destaca-se o reconhecimento do direito ao meio ambiente ecologicamente equilibrado como direito fundamental. Além disso, não se restringiu à atual Constituição prever o meio ambiente saudável como direito subjetivo, tendo ultrapassado a concepção individualista dos direitos subjetivos ao defini-lo como bem de uso comum do povo e essencial à sadia qualidade de vida.

Para Paulo de Bessa Antunes (2005), a própria previsão, no art. $5^{\circ}$ da $\mathrm{CF} / 88$, da ação popular com objetivo de proteção do meio ambiente leva ao reconhecimento do direito ao meio ambiente sadio como direito fundamental:

Ora, se é uma garantia fundamental do cidadão a existência de uma ação constitucional com a finalidade de defesa do meio ambiente, tal fato ocorre em razão de que o direito ao desfrute das condições saudáveis do meio ambiente é, efetivamente, um direito fundamental do ser humano. (Antunes, 2005, p. 19)

Portanto, como direito materialmente fundamental constitucionalmente garantido que é, o direito ao meio ambiente ecologicamente equilibrado possui, assim como os demais direitos fundamentais, aplicabilidade imediata, nos termos do que é determinado pelo $\S 1^{\circ}$ do art. $5^{\circ}$ da $\mathrm{CF} / 88$ : " $\$ 1^{\circ}$ - As normas definidoras dos direitos e garantias fundamentais têm aplicação imediata." Ou seja, a efetivação da tutela ambiental não depende de qualquer regulamentação infraconstitucional prévia.

O Supremo Tribunal Federal, inclusive, já afirmou ser o direito ao meio ambiente sadio um direito fundamental de terceira dimensão, o que ocorreu no julgamento do Mandado de Segurança ${ }^{\circ} 22.164 / \mathrm{SP}$ :

[...] A questão do direito ao meio ambiente ecologicamente equilibrado - direito de terceira geração - princípio da solidariedade - o direito a integridade do meio ambiente típico direito de terceira geração - constitui prerrogativa jurídica de titularidade coletiva, refletindo, dentro do processo de afirmação dos direitos humanos, a expressão significativa de um poder atribuído, não ao indivíduo identificado em sua singularidade, mas, num sentido verdadeiramente mais abrangente, a própria coletividade social. [...] (STF. Mandado de Segurança ${ }^{\circ}$ 22.164/SP. Relator Ministro Celso de Mello. Data do julgamento: 30/10/1995)

No âmbito da legislação infraconstitucional brasileira, importante destacar a Lei $\mathrm{n}^{\mathrm{o}}$ 6.938/81, que instituiu a Política Nacional do Meio Ambiente, apresentou a definição de 
meio ambiente ("conjunto de condições, leis, influências e interações de ordem física, química e biológica, que permite, abriga e rege a vida em todas as suas formas") e, antes mesmo da Constituição de 1988, determinou a harmonização entre os direitos ao desenvolvimento econômico e à proteção do meio ambiente. Abaixo transcreve-se o art. $2^{\circ}$ de referida Lei.

\begin{abstract}
Art. $2^{\circ}$. A Política Nacional do Meio Ambiente tem por objetivo a preservação, melhoria e recuperação da qualidade ambiental propícia à vida, visando assegurar, no País, condições ao desenvolvimento sócioeconômico, aos interesses da segurança nacional e à proteção da dignidade da vida humana.
\end{abstract}

Verifica-se que a Constituição Federal de 1988 adota a mesma vertente já prevista na Lei $\mathrm{n}^{\circ} 6.938 / 81$, que busca garantir o desenvolvimento nacional como um dos objetivos fundamentais da nação (art. $3^{\circ}, \mathrm{II}, \mathrm{CF} / 88$ ), mas sempre observando a dignidade da pessoa humana. $\mathrm{E}$, tratando-se o direito a um meio ambiente equilibrado e protegido de uma das vertentes do princípio da dignidade da pessoa humana, conclui-se ser essencial à sadia qualidade de vida a proteção ambiental associada ao desenvolvimento nacional.

Portanto, pode-se afirmar que tanto a Lei ${ }^{0} 6.938 / 81$, como a atual Constituição Brasileira, adotaram expressamente o princípio do desenvolvimento sustentável, o que pode ser exemplificado através do art. $170, \mathrm{IV}$, da $\mathrm{CF} / 88$, que prevê que o princípio da defesa do meio ambiente representa um dos princípios gerais da atividade econômica.

Somente dessa forma, associando-se desenvolvimento com proteção efetiva do meio ambiente, estará assegurada a preservação da vida e da dignidade da pessoa humana, todos direitos fundamentais do homem expressamente reconhecidos em nossa Constituição Federal.

\title{
4 O DEVER CONSTITUCIONAL DE DEFESA E PRESERVAÇÃO DO MEIO AMBIENTE
}

Conforme explicitado no tópico anterior, o direito a um meio ambiente ecologicamente equilibrado tem natureza de direito público subjetivo indisponível, podendo, portanto, ser exercitado em face do Poder Público, a quem incumbe o dever constitucional de protegê-lo. Nas palavras de Édis Milaré (2007, p. 235): “cria-se para o Poder Público um dever constitucional, geral e positivo, representado por verdadeiras obrigações de fazer, vale dizer, de zelar pela defesa (defender) e preservação (preservar) do meio ambiente.".

Entretanto, importante destacar que o mesmo dever de proteção ambiental imposto ao Poder Público se estende a toda a coletividade. O renomado jurista Celso Antonio Pacheco Fiorillo (2002) assim destaca o dever de preservação do meio ambiente:

\footnotetext{
O bem ambiental, fundamental, como declara a Carta Constitucional, e porquanto vinculado a aspectos de evidente importância à vida, merece tutela tanto do Poder Público como de toda a coletividade, tutela essa consistente num dever, e não somente em mera norma moral de conduta. (Fiorillo, 2002, p. 14)
}

O Princípio da Cooperação, também conhecido como Princípio da Participação, reza que a proteção do meio ambiente não se constitui como tarefa unicamente do Estado, devendo haver a cooperação entre os Estados na comunidade internacional e, com maior intensidade, a participação da população como um todo. Dessa forma, engloba o Princípio da Cooperação tanto o Princípio da Cooperação Internacional como o Princípio da Participação da Sociedade, necessitando este último, para sua garantia, que sejam postos em prática o Princípio da Informação e também o da Educação Ambiental, previstos no inciso VI do $\S 1^{\circ}$ do art. 225, da Constituição Brasileira. 
O Princípio da Educação Ambiental destaca a necessidade da conscientização ecológica da população, titular do direito ao meio ambiente ecologicamente equilibrado. A educação ambiental, como forma de construção de valores sociais e atitudes voltadas à preservação do meio ambiente, trata-se de um componente que deve estar permanentemente inserido na educação nacional, em todos os níveis do processo pedagógico, seja através do ensino formal, desenvolvido nas instituições de ensino, ou através de práticas educativas voltadas para a população como um todo, que se denominou educação ambiental não formal. Celso Antonio Pacheco Fiorillo (2002) elenca benefícios decorrentes da educação ambiental:

Educar ambientalmente significa: a) reduzir os custos ambientais, à medida que a população atuará como guardiã do meio ambiente; b) efetivar o Princípio da Prevenção; c) fixar a ideia de consciência ecológica, que buscará sempre a utilização de tecnologias limpas; d) incentivar a realização do Princípio da Solidariedade, no exato sentido que perceberá que o meio ambiente é único, indivisível e de titulares indetermináveis, devendo ser justa e distributivamente acessível a todos; e) efetivar o Princípio da Participação, entre outras finalidades. (Fiorillo, 2002, p. 41)

Toshio Mukai (2002) afirma se consolidar o Princípio da Cooperação através de uma atuação conjunta do Estado e da sociedade. Tal princípio deixa clara a necessidade de se priorizar a informação e a ampliação da participação popular nos processos da política ambiental, dotando-a de flexibilidade, legitimidade e eficácia.

Inclusive, fundamental a participação da comunidade, eis que, normalmente, a população é quem primeiro toma conhecimento da ocorrência do dano ambiental, razão pela qual se impõe às pessoas o dever de, individualmente, preservar o bem ambiental, cabendo-lhes também o dever de defendê-lo, através da denúncia e busca da reparação dos danos por eles constatados.

Assim, a Constituição Federal, consagrando o Princípio da Cooperação/Participação, trouxe em seu art. 225 a determinação do dever de atuação conjunta do Estado e da sociedade civil na defesa e preservação do meio ambiente. Tal se dá através da atuação de organizações ambientalistas, de sindicatos, associações, indústria, dentre outros organismos sociais comprometidos com a causa ambiental, a quem se possibilita a utilização do instrumento da ação civil pública para fins de garantia da proteção do meio ambiente.

Porém, tal atuação organizacional não exclui a participação individual de cada cidadão, que também possui a responsabilidade de preservar os bens ambientais, bem como de se utilizar dos meios de defesa do meio ambiente, tais como os instrumentos de denúncia de danos ambientais direcionados ao Ministério Público ou aos órgãos de fiscalização ambiental do Estado, assim como a ação popular, que tem o cidadão como legitimado ativo e que visa, dentre outros objetivos, a proteção do bem ambiental.

Ora, eventual omissão no dever de proteção ambiental, tanto por parte do Poder Público como da sociedade, gera prejuízo a ser suportado por toda a coletividade, na presente e, também, nas futuras gerações, já que o meio ambiente ecologicamente equilibrado se trata de direito de natureza difusa, razão pela qual tem a população, em conjunto com o Estado, o dever constitucional de atuar ativamente na preservação desse direito fundamental.

\section{Conclusão}

O presente trabalho, através da pesquisa bibliográfica em obras dos mais renomados autores do Direito Ambiental e do Direito Constitucional, e também da consulta a artigos, legislação, jurisprudência e reportagens disponibilizadas nos diversos veículos de comunicação, restou por demonstrar o grande estímulo que os tratados e convenções internacionais sobre meio 
ambiente representaram para a constitucionalização e regulamentação da tutela ambiental nos mais diversos países do mundo. Podemos destacar, dentre os mais importantes encontros internacionais relacionados à questão ambiental, os realizados em Estocolmo, na Suécia, em 1972, e no Rio de Janeiro, no Brasil, em 1992.

Nesse contexto, os mais recentes modelos constitucionais têm previsto expressamente o direito ao meio ambiente ecologicamente equilibrado, além de terem elevado a tutela ambiental ao nível de direito fundamental, reconhecendo o citado direito como um direito fundamental de terceira dimensão.

Estando em pé de igualdade com os demais direitos fundamentais, inclusive o direito de propriedade e o direito ao desenvolvimento, o direito ao meio ambiente sadio pode, em situações concretas, entrar em conflito com outros direitos fundamentais, principalmente os referidos direitos de propriedade e ao desenvolvimento. Porém, esses conflitos são passíveis de serem solucionados com a adequada aplicação do princípio do desenvolvimento sustentável, conceito mundialmente difundido que estabelece a conciliação entre a proteção ambiental e o desenvolvimento econômico.

No Brasil, destacamos o fato de ter sido a atual Constituição a primeira a determinar expressamente o direito ao meio ambiente ecologicamente equilibrado, direito reconhecidamente fundamental, tratando-se também do primeiro diploma constitucional brasileiro a instituir o dever de preservação ambiental, atribuído tanto ao Poder Público como a toda a coletividade. A Carta Magna de 1988 dedicou um capítulo inteiro à questão ambiental e estabeleceu a observância do já referido princípio do desenvolvimento sustentável. A Constituição Federal do Brasil de 1988 ressaltou, inclusive, o fato de não ser a proteção do meio ambiente tarefa apenas do Estado, isoladamente, tendo sido atribuída também à sociedade a responsabilidade pela busca do meio ambiente ecologicamente equilibrado.

Chega-se, portanto, à conclusão de que é efetivo o reconhecimento do direito ao meio ambiente ecologicamente equilibrado como direito fundamental e do dever de preservação imposto aos poderes estatais e à coletividade, já regulamentados por normas protetivas do meio ambiente, regulamentação essa que tem evoluído bastante nos últimos anos. Porém, o grande problema que se mostra nos dias de hoje é a dificuldade em dar aplicabilidade a essas normas. A garantia da tutela desse direito fundamental, tanto no âmbito do direito interno como do direito internacional ambiental, depende, na prática, de ações concretas quanto ao cumprimento do dever de defesa do meio ambiente e da observância dos princípios da precaução e do desenvolvimento sustentável. Além disso, de acordo com François Ost (1995):

[...] o direito administrativo do ambiente (manifestado aqui pelo sistema de licenças de exploração) não constitui, necessariamente, uma proteção eficaz da natureza e dos seus usos. No quadro de um Estado industrial, onde as elites políticas ou as elites econômicas se interpenetram, e reforçam mutuamente os seus interesses respectivos, o direito regulamentar, embora concedendo aos cidadãos uma ilusão de proteção, pode, em alguns casos, acentuar mais do que travar as atividades poluentes. (Ost, 1995, P. 78)

Frequentemente, temos visto na mídia alertas de uma iminente, senão já instalada, crise ambiental global. A própria natureza tem manifestado esses alertas, que demonstram a grave situação atual do meio ambiente, como, por exemplo, através das bruscas alterações climáticas, efeito estufa, temporais, tornados, entre outros. Cabe aos Poderes Públicos dos países de todo o Mundo, já que o meio ambiente não se limita às fronteiras geográficas e à humanidade como um todo, promover uma integração geral para que se efetive, na prática, a garantia de um meio ambiente sadio às atuais e futuras gerações. 


\title{
REFERÊNCIAS
}

ANTUNES, Paulo de Bessa. Direito Ambiental. 8 ed. Rio de Janeiro: Lumen Juris, 2005.

BRASIL. Constituição (1988). In Presidência da República. Disponível em: < http://www.planalto. gov.br/ccivil_03/constituicao/constitui\%C3\%A7ao.htm>.

BRASIL. Lei 6.938 (1981). In Presidência da República. Disponível em: < http://www.planalto. gov.br/ccivil_03/Leis n ${ }^{\circ}$ 6938.htm>.

CANOTILHO, José Joaquim Gomes e José Rubens Morato Leite (organizadores). Direito Constitucional Ambiental Brasileiro. SãoPaulo: Saraiva, 2007.

FIORILlO, Celso Antônio Pacheco. Curso de Direito Ambiental Brasileiro. 3 ed. ampl. São Paulo: Saraiva, 2002.

MILARÉ, Édis. Legislação Ambiental do Brasil. São Paulo: APMP, 1991.

MILARÉ, Édis. Direito do Ambiente. 5 ed. São Paulo: Editora Revista dos Tribunais, 2007.

MORAES, Alexandre de. Direito Constitucional. 20 ed. São Paulo: Atlas, 2006.

MUKAI, Toshio. Direito Ambiental Sistematizado. 4 ed. São Paulo: Forense, 2002.

OST, François. A Natureza à Margem da Lei. Lisboa: Instituto Piaget, 1995.

SILVA, José Afonso da. Direito Ambiental Constitucional. 4 ed. São Paulo: Malheiros, 2002.

\section{THE ECOLOGICALLY BALANCED ENVIRONMENT AS A FUNDAMENTAL RIGHT AND DUTY IN THE BRAZILIAN FEDERAL CONSTITUTION OF 1988}

\begin{abstract}
The present research aims the analysis, through bibliographical studies, of the recognition by the Brazilian's Federal Constitution of 1988 of the status of Fundamental Right given to the Right to an Ecologically Balanced Environment, and also the exam of the imposition to the Government and to society as a whole of the Fundamental Duty to protect the environment. On that matter, it is possible to notice that there are other Fundamental Rights besides the ones listed in the Fifth Article of Brazilian's Federal Constitution, for example the Right to an Ecologically Balanced Environment, stated in the article 225 of this Constitution. Further on, an analysis of Brazilian's constitutional and legislative development has been made related to the protection of an ecologically balanced environment which occurred in a way to prevent any damage to economic development, that is when the concept of sustainable development was inserted in the Federal Constitution. Finally, this research intended to show that the article 225 of the Federal Constitution imposed not only to the Public Administration, but also to all society, the duty of environment protection.
\end{abstract}

Keywords: ecologically balanced environment, fundamental right, common duty 